\title{
Clinicopathologic Analysis of 90 Fibro-Osseous Jaw Lesions: A Single Institutional Experience
}

Adeola Ladeji ${ }^{*}$, Oluwafemi Adesina ${ }^{2}$, Adetayo Aborisade ${ }^{3}$, Mofoluwaso Olajide ${ }^{1}$, Olasunkanmi Kuye ${ }^{2}$, Olalekan Aderemi $^{1}$, Kehinde Adebiyi ${ }^{1}$, Ikechukwu Okoye ${ }^{1}$, Busuyi Olowe ${ }^{1}$

${ }^{1}$ Department of Oral Pathology and Oral Medicine, Lagos State University College of Medicine, Ikeja, Lagos, Nigeria

${ }^{2}$ Department of Oral and Maxillofacial Surgery, Lagos State University College of Medicine, Ikeja, Lagos, Nigeria

${ }^{3}$ Department of Oral Diagnostic Sciences, Faculty of Dentistry, Bayero University, Kano Nigeria

DOI: $10.36348 /$ sjpm.2020.v05i05.014

| Received: 29.04.2020 | Accepted: 10.05.2020 | Published: 30.05 .2020

*Corresponding author: Adeola Ladeji

\section{Abstract}

Background: Fibro-osseous jaw lesions are a group of tumours and proliferative disorders which present similar clinicopathological features. They comprise a range of developmental, reactive and neoplastic lesions characterized by replacement of normal bone by fibrous tissue, with subsequent formation of new mineralized tissue. Making diagnosis of fibro-osseus lesions may be challenging for clinicians and pathologists alike, owing to their overlapping clinicopathology. Objectives: This study aims to determine the pattern and clinicopathological distribution of fibroosseous lesions of the jaws over a 7-year period. Methodology: This study retrospectively reviewed 90 fibro-osseous lesions diagnosed at the Oral Pathology laboratory of the department of Oral Pathology and Oral Medicine, Lagos State University College of Medicine, over a period of seven years (January 2013 to January 2019). Information regarding the type, frequency, age, sex and site distribution of FOLs were retrieved from the archival records of the Oral Pathology laboratory. Result: Fibro-osseous lesions (FOLs) of the jaws constituted $8.94 \%$ of all biopsies seen within the 7-year study period. Ossifying fibromas were the commonest FOL types accounting for $63.3 \%$ of all FOLs, followed by fibrous dysplasias at $20 \%$. Lesions were observed within the age range of 9-72 years with an overall mean age of $31.9 \pm 15.5$ years for all FOLs, $38.5 \pm 1.5$ for Ossifying fibroma and 13.3 \pm 2.5 years for fibrous dysplasia. Female predilection for FOLs was recorded at a Male: Female ratio of 1:2.2. Mandible was the observed site of predilection for Ossifying fibroma, while the reverse was observed for Fibrous dysplasia. Conclusion: FOLs are relatively common jaw lesions, with ossifying fibromas occurring more frequently than others. Making an accurate diagnosis of FOLs in resource limited settings is greatly dependent on the availability of detailed clinical information, owing to their similar histopathologic appearances.

Keywords: Fibro-osseus, Fibrous dysplasia, ossifying fibroma, cemento-osseus dysplasia.

Copyright @ 2020: This is an open-access article distributed under the terms of the Creative Commons Attribution license which permits unrestricted use, distribution, and reproduction in any medium for non-commercial use (NonCommercial, or CC-BY-NC) provided the original author and sources are credited.

\section{INTRODUCTION}

Waldron and Giansanti presented the earliest discussions on fibro-osseous lesions(FOLS) with a twopart clinico-radiologic-histologic review of 65 cases[1]. They highlighted that the common central denominator for FOLS is the replacement of normal healthy bone by a benign fibro-cellular tissue with varying amounts of mineralized substances. Due to these similar histomorphologic features of fibro-cellular tissue and mineralized matrix, arriving at a definitive diagnosis requires analysis of the presenting clinical and radiological features. Despite indistinct clinicoradiologic features amongst FOLS, Slootweg and Muller [2] proposed using imperceptible blending of lesional bone with adjacent healthy jawbone as the differentiating factor between fibrous dysplasia and the other FOLS. Eisenberg and Eisenbud [3] emphasized that in the absence of this information, "pathologists today will often rightly decline to render a definitive diagnosis and can only make use of the noncommittal designation of benign fibro-osseous lesions. Even with this clinico-radiologic information, adjunctive tests such as immunohistochemistry and molecular studies may further be needed to differentiate sub-types of this heterogeneous group.

FOLS also lack a universally accepted classification system with different classification systems employing different and sometimes overlapping grouping criteria. Waldron first proposed a working classification in 1985[4] which grouped FOLS 
into the three common subgroups of Fibrous Dysplasia(FD), the reactive cemento-osseous dysplasias(COD) which are now known simply as Osseous Dysplasias(OD) and the fibro-osseous neoplasms of Ossifying fibroma(OF). Various modifications of this classification have been added over the years with each group getting further divided into subgroups and subtypes; an updated classification scheme for FOLS reviewed by Rajpal et al. [4] explored all the classification systems. Varying controversies have trailed the components of each subgroup with some authors arguing that periapical osseous dysplasias(POD) and focal osseous dysplasia(FOD) are the same pathologic conditions albeit at different locations[5] while others believed florid osseous dysplasia(FCOD) is an exuberant form of FOD and not a totally different entity[2], this controversy is more represented in the Eversole classification of FOLS in 2008 wherein osseous dysplasias only have FOD and FCOD as the only types[4]. W.H.O 2017[6] classification of odontogenic tumors also underlined the arguments surrounding the gnathic (or otherwise) origin of OF by classifying it exclusively as a mesenchymal benign odontogenic tumor. In spite of these plethoras of classifications systems, most authors in documented literature make use of the working classification of Waldron (and its modifications) to sub-classify FOLS due to its simplicity [2,7,8]. For the purpose of clarity and deductive comparisons with earlier literature, we will make use of Speight and Carlos classification of 2006 in this retrospective study.

Greater than $70 \%$ of all FOLS occur in the head and neck region with a marked predilection for the mandible followed by the maxilla: other facial bones including the paranasal sinuses, sphenoid bone and other skull bones are also commonly involved [9]. Asides the common subtypes, other spectrum of FOLS found in long bones include osteofibrous dysplasia and adamantinoma of long bones [10]. MacDonaldJankowski et al. [3] highlighted the differences between gnathic and extragnathic FD and cited the differences in the ossification patterns as the reason for this discrepancy. Various jaw entities, such as osteoblastoma, osteoid osteoma, Paget disease of bone, et al. have been sub-classified in the FOLS category by different authors [7].

Despite contrasting epidemiological differences in FOLS[2,7] there is relatively high prevalence of FOLS in orofacial tumors[11]: while some subtypes are very common, some other subtypes are very rare. Racial and sex predilections for a subset of fibro- osseous lesions has also been reported [12]. Clinical features of FOLS vary from asymptomatic incidental radiological findings as commonly observed in ODs to painless swelling observed in other subtypes. Painful swelling was also observed in some FOLS cases especially in patients with the juvenile ossifying fibroma (JOF) subtype. FOLS may also be associated with significant cosmetic and functional disturbances and reach gigantic sizes especially in black Africans [13]. Radiographically, FOLS present a spectrum of radiodensities ranging from simple radiolucencies to mixed radiolucent/ radiopaque lesions to frank radioopacities. Majority of FD and OF presented with the mixed radiodensities while most ODs presented with frank radiopacities[7]. Petrikowski et al.[3] however that FD has essential distinct radiographic features of alteration of the lamina dura to the abnormal bone pattern, and narrowing of the periodontal ligament space which is in contrast to the displacement of teeth and / or resorption of roots in $\mathrm{OF}$

FOLS are grouped together because of their histologic similarities and morphologic attributes of fibrocellular appearance with mineralized substances. The relative proportions of the fibrocellular tissue and degree of collagenzation however vary between subtypes[11] (refs), population of mineralized substances also are discrepant with relative differences between woven bone, lamellar bone and cemental-like tissue in each subtype. Other features common to FOLS include the presence of multinucleated giant cells(MGCS), stromal hemorrhage, stromal mitosis[14]. Fibrous elements and ossification variations observed in FOLS is tabulated in Table 1.

Due to the difficulty of routine histological procedures to differentiate FOLS, adjunct methods such as special histochemical stains have been utilized including but not restricted to Masson's trichrome and modified tetrachrome (woven vs lamellated bone)[14], modified Attwood's stain and Potassium monopersulfate-aldehyde fuchsin stain (oxytalan fibers). Immunohistochemical markers have also been utilized especially to differentiate $\mathrm{OF}$ and FD with the use of antibodies to RunX2, osteopontin, osteocalcin and DMP-1[15].

Despite the unknown etiologies of subtypes of FOLS, an activating point mutation of the alpha subunit of the stimulatory $\mathrm{G}$ protein gene (GNAS) has been identified in FD[16]. Also, CDC73 gene mutation has also observed in about $30-50 \%$ of OF[11]. These molecular characterizations can thus be used to definitively make diagnosis of FD and OF respectively and can serve as adjunct to histological diagnosis and a much more reliable tool than immunohistochemistry [15]. Alawi et al. [8] and Jankowski et al. [8] reported a predilection of FOLS for people of African descent; in spite of this, there are relatively few documented reports on prevalence of FOLs from Sub-Saharan African [8].

The aim of this study is thus to present the socio-demographic presentation of FOLS seen at the Oral Pathology laboratory of the Lagos State University College of Medicine, Lagos, Nigeria. 


\section{MATERIALS AND METHODS}

The sample involved all the cases found in the archives of the Department of Oral Pathology and Oral medicine using the biopsy registers of the oral pathology laboratory over a period of seven years (January 2013 to January 2019). The clinical parameters included were age, sex and location. Definitive diagnoses and subtype of FOLS were also retrieved.

Regarding site distribution, the maxilla was divided into two anatomic regions as anterior (midline to distal surface of canine) and posterior (mesial surface of first premolar distally). The mandible was divided into four anatomic regions such as anterior (midline to distal surface of canine), posterior (mesial surface of first premolar distally), angle (from distal of third molar to the inferior portion of ramus), and ramus (upper portion of the ramus beyond the occlusal plane).

Hematoxylin and Eosin stained glass slides of FOLs were also retrieved and reviewed independently by two oral pathologists for reconfirmation of the diagnosis. FOLS were classified using Paul M. Speight \& Roman Carlos Classification [4].
A. Fibrous Dysplasia
B. Monostotic FD
C. Polyostotic FD
D. Craniofacial FD

E. Osseous Dysplasia

F. Periapical Osseous Dysplasia

G. Focal Osseous Dysplasia

H. Florid Osseous Dysplasia

I. Familial Gigantiform Cementoma

J. Ossifying Fibroma

K. Conventional Ossifying Fibroma

L. Juvenile Trabecular Ossifying Fibroma

M. Juvenile Psammomatoid Ossifying Fibroma

\section{DATA ANALYSIS}

Data were analyzed using Stata 14 (Statacorp College Station, Texas). Descriptive statistics carried out were for socio-demographic variables such as age, gender, and location of tumor; prevalence of the lesions was determined and expressed in frequencies as percentages. Means and standard deviations were used for continuous variables while proportions and tables were used for categorical variables. The independent ttest and ANOVA were used to compare differences in the age; this was after Levene test and Shapiro-Wilk test had been used to confirm homogeneity of variance and normality of distribution respectively. Welch's Ttest and ANOVA were used in case of any deviation from normality of data or homogeneity of variance, otherwise non-parametric Kruskal - Wallis was used to determine average of means between variables. The
Chi-square test was used to compare the proportion of the different types of FOLs and across the age groups, locations, histologic diagnosis and sub-classification. All tests were carried out with significance accepted at $\mathrm{p}<0.05$.

\section{RESULTS}

A total of $90(8.94 \%)$ cases of FOLs from total of 1007 biopsies was retrieved and documented from the biopsy records of the Oral pathology laboratory. Of the subtypes of FOLS, OFs accounted for $63.3 \%(n=57)$ with ODs representing $16.7 \% \%(\mathrm{n}=15)$ and FD $20 \%(\mathrm{n}=18)$. Of individual lesions, COF accounts for $54.4 \%(n=49)$ of all the FOLS followed by FD at $20 \%(n=18)$, POD had the least presentation at $3.3 \%(n=3)($ Table 1$)$.

\section{Age and Sex}

FOLS presented a mean age of 31.9 years \pm 15.5 ranging from 9 years to 72 years with median age of 29.5 years. Most of the FOLs were seen in the second decade $(22,24.4 \%)$ and third decades $(21$, $23.3 \%$ ). The mean ages for individual lesion for OF is 38.5 years \pm 1.5 years and FD at the lowest of 13.3 years \pm 2.5 years $(\mathrm{p}=0.0001)$ The male $(31.1 \%, \mathrm{n}=28)$ : female $(68.9 \%, \mathrm{n}=62)$ ratio for the FOLs was $1: 2.2$ with a female predilection (Table 2 ). The mean age observed for sex was 28 years \pm 15.7 years for males and 33.5 years \pm 15.1 for females which was not statistically significant

\section{Location}

There is a slight mandibular predilection (58.9\%, $\mathrm{n}=53$ ) with a maxilla: mandibular ratio of 1:1.4. The maxilla: mandibular ratio also varies across sex with a maxillary predilection $(60.7 \%)$ for FOLS involving the male gender while the female gender has a $67.7 \%$ mandibular predilection $(\mathrm{p}=0.02)$. FOLs involving the maxilla are more common in the second decade $(45.9 \%, \mathrm{n}=17)$ and fourth decade $(18.9 \%, \mathrm{n}=7)$ : mandibular FOLs are however more common in the third decade $(33.9 \%, \mathrm{n}=18)$ and fourth decade $(22.6 \%$, $\mathrm{n}=12$ ): with a statistically significant $\mathrm{p}$ value at 0.0001 .

The mean age across the maxilla and mandible is also significant as the mean age of presentation of FOLS for maxillary lesions is 27.3 years \pm 16.7 while the mean age for mandibular FOLs is 35.2 years \pm 13.5 ( $\mathrm{p}=0.004$ ). Of site distribution, the mandibular posterior region (with or without involvement of the mandibular anterior) was the most involved $(55.6 \% \%$, $\mathrm{n}=50)$ followed by the posterior maxilla $(32.2 \%, \mathrm{n}=29)$. The mandibular posterior region was also the most commonly involved in the female while the maxillary posterior region was the most commonly involved region in the male with a significant $\mathrm{p}$ value of 0.01 . The mean age across the anatomic site varies significantly from 20 years in the mandibular angle to 39.6 years \pm 10.9 years with mandibular anterior region $(\mathrm{p}=0.02)$. 


\section{Classification and Individual Lesions}

The mean age of subtypes of FOLs ranges from 13.4 years \pm 2.72 for fibrous dysplasia to 39.9 years \pm 17.0 for $\mathrm{OD}(\mathrm{p}=.0001)$. Across the age groups, FD was most common in the first and second decade of life $(100 \%)$, OD commonly found between the third to fifth decades of life $(73.3 \%)$ with the remaining cases involving the sixth and seventh decades $(26.7 \%)$ while OFs are commonly found between the third and fourth decade $(\mathrm{p}=0.0001)$.

There is a general female preponderance for all the subtypes with male to female ratios for each subtype ranging from $1: 1.6$ for $\mathrm{FD}$, to $1: 2.6$ for $\mathrm{FNs}$, this difference is however not statistically significant. As regards the jaws, there are significant variations with predilection from a maxillary predilection for FD (2.6:1) to a mandibular predilection for FNs $(1: 2.4)$ with a p-value of 0.005 . Regarding specific site distribution, FD has a predilection for the maxillary posterior region with anterior extension while OD shows predilection for the posterior regions of both the maxilla and mandible equally. FNs on the other hand express a predilection for the mandibular posterior region

Different individual lesions express predilection for different age groups with OF showing a predilection for third and fourth decade (49.5\%), FD (first and decade decade, 100\%), JOF (second decade, $75 \%$ ), POD (fifth and sixth decade, 100\%), FOD (third and fourth decade, 66.7\%). This is statistically significant at $p$ value of 0.0001 . There are no significant differences of individual lesions predilection across sex (Table 3), however there's significant statistical between predilection for the jaws $(p=0.0001$ and specific regions $(\mathrm{p}=0.0001)$ across the individual lesions.

Table-1: Relative Frequency of Fibro-Osseous Lesions

\begin{tabular}{|c|c|c|}
\hline Type of Lesion & Number of Cases & Percent \\
\hline Fibrous dysplasia & 18 & 20 \\
\hline Osseous dysplasia & 3 & \\
\hline Periapical & 12 & 3.3 \\
\hline Focal & & 13.3 \\
\hline Ossifying fibroma & 49 & \\
\hline Ossifying fibroma & 8 & 54.4 \\
\hline $\begin{array}{c}\text { Juvenile ossifying } \\
\text { Fibroma }\end{array}$ & 90 & 8.9 \\
\hline Total & 300 \\
\hline
\end{tabular}

Mean age across Lesion $(\mathrm{p}=.0001)$

Table-2: Sex Distribution of Fibro-Osseous Lesions of the Jaws

\begin{tabular}{|l|c|c|c|c|c|}
\hline & \multicolumn{2}{|c|}{ Male } & \multicolumn{2}{c|}{ Female } & \\
\hline \multicolumn{1}{|c|}{ Type of Lesion } & No & $\%$ & No & $\%$ & Female: Male Ratio \\
\hline Fibrous Dysplasia & 7 & 38.9 & 11 & 61.1 & $1: 1.6$ \\
\hline Osseous Dysplasia & & & & & $1: 2$ \\
\hline Periapical & 1 & 33.3 & 2 & 66.7 & $1: 2$ \\
\hline Focal & 4 & 33.3 & 8 & 66.7 & $1: 3$ \\
\hline Ossifying Fibroma & & & & & $1: 1$ \\
\hline Ossifying fibroma & 12 & 24.5 & 37 & 75.5 & $1: 2.2$ \\
\hline $\begin{array}{c}\text { Juvenile ossifying } \\
\text { fibroma }\end{array}$ & 4 & 50 & 4 & 50 & \\
\hline Total & 28 & 31.1 & 62 & 68.9 & \\
\hline
\end{tabular}

Table-3: Age Distribution of Fibro-Osseous Lesions of the Jaws

\begin{tabular}{|c|c|c|c|c|c|c|c|}
\hline \multicolumn{7}{|c|}{ AGES(YEARS) } \\
\hline Type of Lesion & $0-9$ & $10-19$ & $20-29$ & $30-39$ & $40-49$ & $50-59$ & $60-69$ \\
\hline Fibrous Dysplasia & 2 & 16 & 0 & 0 & 0 & 0 & 0 \\
\hline Osseous Dysplasia & & & & & & & \\
\hline Periapical & 0 & 0 & 0 & 0 & 2 & 1 & 0 \\
\hline Focal & 0 & 0 & 6 & 2 & 1 & 1 & 2 \\
\hline Ossifying Fibroma & & & & & & & \\
\hline Ossifying fibroma & 0 & 0 & 13 & 17 & 7 & 11 & 1 \\
\hline $\begin{array}{c}\text { Juvenile ossifying } \\
\text { fibroma }\end{array}$ & 0 & 6 & 2 & 0 & 0 & 0 & 0 \\
\hline Total & 2 & 22 & 21 & 19 & 10 & 13 & 3 \\
\hline
\end{tabular}


Table-4: Site Distribution of Fibro-Osseous Lesions of The Jaws

\begin{tabular}{|c|c|c|c|c|c|c|c|c|c|c|c|c|c|}
\hline & Maxilla & & & & & Mar & ible & & & & & & \\
\hline $\begin{array}{ll}\text { Type } & \text { of } \\
\text { Lesion } & \\
\end{array}$ & $\begin{array}{l}\text { Number } \\
\text { of cases }\end{array}$ & Ant & Pos & Ant/Pos & Total & Ant & Pos & Ant/Pos & $\begin{array}{l}\text { Ant/Pos/ } \\
\text { Ramus }\end{array}$ & Ramus & Angle & Total & $\begin{array}{l}\text { Max/Mand } \\
\text { Ratio }\end{array}$ \\
\hline $\begin{array}{l}\text { Fibrous } \\
\text { Dysplasia }\end{array}$ & 18 & 4 & 1 & 8 & 13 & 1 & 4 & 0 & 0 & 0 & 0 & 5 & $2.6: 1$ \\
\hline $\begin{array}{l}\text { Osseous } \\
\text { Dysplasia }\end{array}$ & & & & & & & & & & & & & \\
\hline Periapical & 3 & 1 & 1 & 0 & 2 & 1 & 0 & 0 & 0 & 0 & 0 & 1 & $2: 1$ \\
\hline Focal & 12 & 0 & 5 & 0 & 5 & 0 & 7 & 0 & 0 & 0 & 0 & 7 & $1: 1.4$ \\
\hline $\begin{array}{l}\text { Ossifying } \\
\text { Fibroma }\end{array}$ & & & & & & & & & & & & & \\
\hline $\begin{array}{l}\text { Ossifying } \\
\text { fibroma }\end{array}$ & 49 & 3 & 4 & 4 & 11 & 4 & 22 & 11 & 0 & 0 & 1 & 38 & $1: 3.5$ \\
\hline $\begin{array}{l}\text { Juvenile } \\
\text { ossifying } \\
\text { fibroma }\end{array}$ & 8 & 0 & 3 & 3 & 6 & 0 & 2 & 0 & 0 & 0 & 0 & 2 & $3: 1$ \\
\hline
\end{tabular}

Maxilla: mandibular ratio across Sex $(\mathrm{p}=0.02)$.

Maxilla: mandibular ratio across Decade $(\mathrm{p}=0.0001)$

Mean age across the maxilla and mandible $(\mathrm{p}=0.004)$

Mean age across anatomic sites $(\mathrm{p}=0.02)$

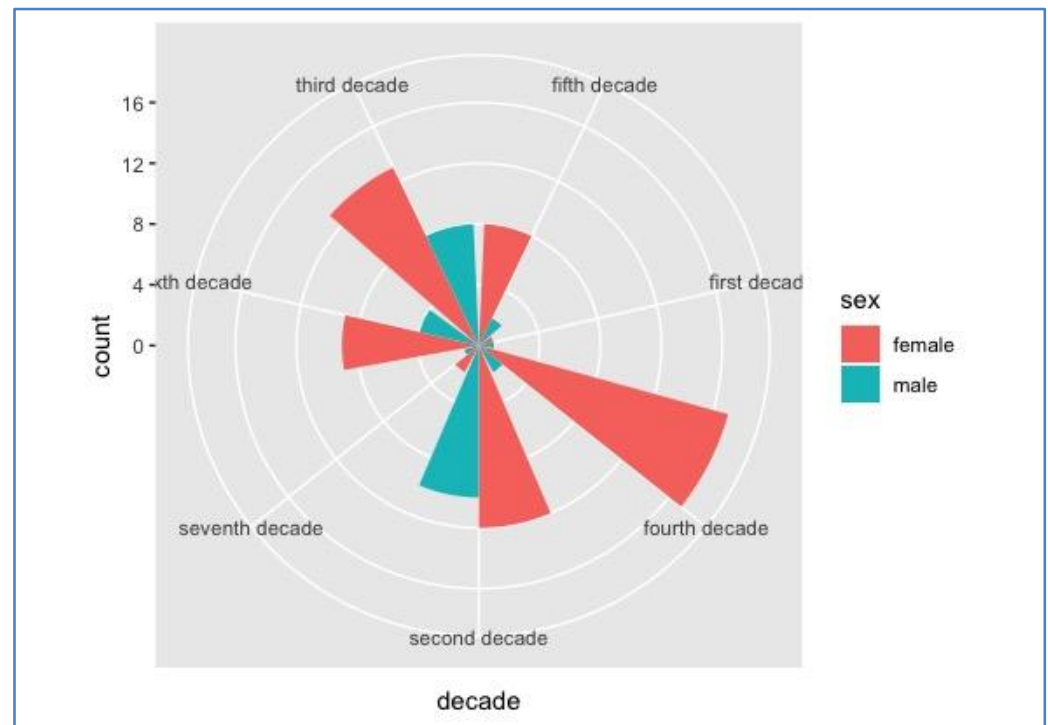

Fig-1: Relationship between Gender and decade of occurrence of Fibro osseous lesions

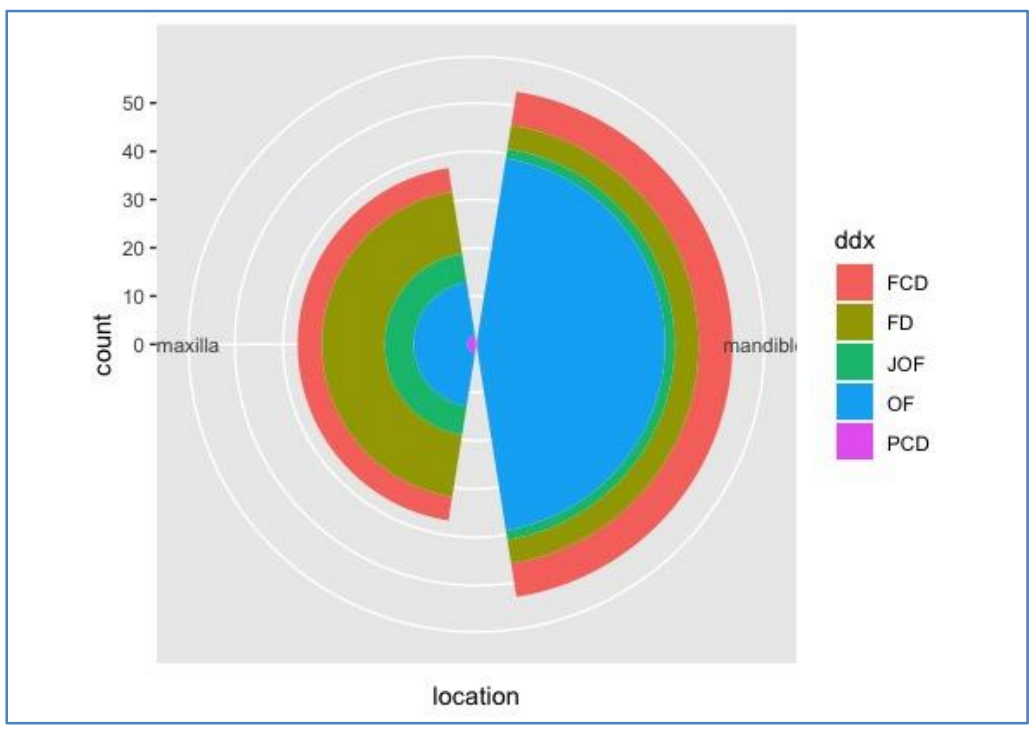

Fig-2: Distribution of Fibro osseous lesions within the Jaw bones 


\section{DISCUSSION}

Despite FOLS being a relatively common group of lesions, there is paucity of reports on its epidemiology as it pertains to geography, race and gender. However, there have documented reports and reviews on its relative frequencies and clinicopathological and radiological features [2, 3, 17]. Retrospective studies detailing individual institution's pattern of FOLS presentation has been widely reported in Western literature [18], Asia [19] and Sub-Saharan Africa $[8,20]$.

In this study, FOLs represent $8.9 \%$ of all biopsied cases which is in tandem with the 8.7-8.9\% reported by Soyele et al. [11] and Fomete et al.[13] in similar Nigerian studies but significantly higher than $1 \%-2.5 \%$ in reported continental studies[2,21]. Bassey et al. and Yamani et al. [13] however observed increased prevalences of $13 \%$ and $13.5 \%$ respectively. This high prevalence in Africans corroborated the findings of Jankowski et al.[3] and a combination of environment and racial factors have been hypothesized to explain this differential prevalence. OF was the most prevalent FOL at $63.3 \%$, in tandem with other Nigerian and African studies with OF prevalence with varying ranges from $50.4 \%-68.3 \%[8,13,22]$. FD prevalence has however been reported in documented studies of Vegas[23], Yoon[11], and other authors[16]. ODs exhibited the least prevalence as observed in most documented studies on FOLs[7,21] despite Waldron et al. [2] reporting OD to be most common FOL. This disparity has been due to the two-pronged reasons of gross underreporting by general practitioners and the lack of need of histology to arrive at its diagnosis [11].

The wide age range of FOLS presentation has also been documented with age from as low as 3years to 70 years reported $[8,22]$. The age range in this study was between 9-72 years with a mean age of 31.9 years, this is tandem with the peak age of 25- 35 years reported by $\mathrm{Su}$ et al. [5], it is however higher than the 11-20 years observed by Abdulahi et al. [20] and 23.5 years reported by Prabhu et al. [21]. These differences in mean age can be due to geographical differences.

OF presented with a mean age of 38.5 years and most commonly found between the third and fourth decade in agreement with the studies of Ogunsalu[17] and Worawongvasu et al. [2]. it also presented a mandibular predilection mostly the mandibular posterior region involvement: all in concordance with documented literature[2,23]. The juvenile variants however only accounted for $14 \%$ of all OFs and $8.9 \%$ of all FOLs with preponderance in the second decade with a mean age of 19 years. this JOF prevalence is higher than the $6.3-7.5 \%$ in Soyele et al. [11] and Phattarataratip et al. [7] and considerably higher than the $0.6 \%$ prevalence observed in the Ugandan study of Muwazi et al. [8]. The reason for this difference in incidence is not clear but the proximity of our institution to a plethora of colleges and high schools could have increased proportion of hospital visits by teenagers and young adults. Though there is a general female predilection for all FOLS, OFs presented male: female ratio of 1:2.6 in tandem with the 2.5 and 2.1 ratio in documented studies $[2,11]$ and higher than the 1.5 ratio observed in the studies of Ogunsalu et al. and Phattarataratip et al. [7]. All documented reports however agreed on a female predilection. Jankowski et al. [3] hypothesized that female sex hormones may play in role in pathogenesis of FOLs especially in pregnancy hence this female predisposition.

FD presented a mean age of 13.4 years and was most commonly seen in the second decade in concordance with the documented studies of Worawongvasu and Regezi[2] and Nigerian studies of Iyogun et al. [24]. The maxillary posterior region predilection in our study for FD also concurs with observed reports in studies of Waldron and Regezi[2]. FD also presented with a female preponderance with male: female ratio of 1:1.6 in tandem with the studies of Prabhu[21]. Other studies however observed equal gender proportion for $\mathrm{FD}[11,22]$.

The marked prevalence for ODs in middle aged African Americans has been widely reported [5, 25 ] with a female predilection. A female presentation in the fourth and fifth decade of life was observed in studies of $\mathrm{Su}$ et al. and Alsufyani[25]. A female predilection was also observed in our study with a mean age of 39.9 years however there was preponderance in the third decade as against the fourth decade in literature. This could be explained by the fact that most of the cases in our study were picked on routine radiography and included in surgery day registers as opposed to other studies where the source was mainly the histopathology biopsy registers. Its predilection for Africans is observed in Nigerian and African studies where prevalence of ODs in all FOLs is between $10 \%$ $12.9 \%$ reported by Muwazi[8] and Iyogun[24]. The prevalence in our study is $16.7 \%$.

Despite distinct clinicopathologic features of each component, meticulous anamnesis with adjunct molecular studies might be the only modality to accurately differentiate amongst FOLs especially between FD and OF. An understanding of the clinicopathologic features is critically important in low to middle income with limited access to advanced pathologic techniques.

\section{REFERENCES}

1. Abramovitch, K., \& Rice, D. D. (2016). Benign fibro-osseous lesions of the jaws. Dental Clinics, 60(1), 167-193.

2. Worawongvasu, R., \& Songkampol, K. (2010). Fibro- osseous lesions of the jaws: an analysis of 122 cases in Thailand. Journal of oral pathology \& medicine, 39(9), 703-708. 
3. MacDonald-Jankowski, D. S. (2004). Fibroosseous lesions of the face and jaws. Clinical radiology, 59(1), 11-25.

4. Rajpal, K., Agarwal, R., Chhabra, R., \& Bhattacharya, M. (2014). Updated classification schemes for fibro-osseous lesions of the oral \& maxillofacial region: a review. IOSR Journal of Dental and Medical Sciences, 13(2), 99-103.

5. Su, L., Weathers, D. R., \& Waldron, C. A. (1997). Distinguishing features of focal cemento-osseous dysplasia and cemento-ossifying fibromas: II. A clinical and radiologic spectrum of 316 cases. Oral Surgery, Oral Medicine, Oral Pathology, Oral Radiology, and Endodontology, 84(5), 540-549.

6. El-Naggar, A. K., Chan, J. K. C., Grandis, J. R., Takata, T., \& Slootweg, P. J. (2017). WHO classification of head and neck tumours. WHO/IARC classification of tumours. World Health Organization.

7. Phattarataratip, E., Pholjaroen, C., \& Tiranon, P. (2014). A clinicopathologic analysis of 207 cases of benign fibro-osseous lesions of the jaws. International journal of surgical pathology, 22(4), 326-333.

8. Muwazi, L. M., \& Kamulegeya, A. (2015). The 5year prevalence of maxillofacial fibro- osseous lesions in U ganda. Oral diseases, 21(1), e79-e85.

9. Megahed, A. S. (2013). Retrospective study for diagnosis and management of fibro-osseous lesions affecting para nasal sinuses.

10. Knapik, J.A.(2012). Fibro-osseous lesions. Surg Pathol Clin, 5(1):201-29.

11. Soyele, O., Aborisade, A., Olatunji, S., Adesina, O., \& Njokanma, A. (2018). Patterns of fibroosseous lesions of the oral and maxillofacial region seen in a tertiary hospital at ile-ife, nigeria. African Journal of Oral and Maxillofacial Pathology and Medicine, 4(1), 16-27.

12. Chauhan, I., Roy, S., Garg, V., \& Manchanda, K. (2014). Fibro-osseous lesions of the jaws: An insight. Int J Contemp Dent Med, 2014, 828-35.

13. Fomete, B., Osunde, O. D., Ogbeifun, J. O., \& Adebayo, E. T. (2016). Fibroosseous lesions of the craniofacial region: A 14 year experience. West Indian Med J, 1-14.

14. Maheshwari, P., Rao, N. N., \& Radhakrishna, R. (2014). Histochemical evaluation of stromal components in fibrous dysplasia, central ossifying fibroma and juvenile ossifying fibroma affecting the jaw bones. Structure, 14(4), 2.
15. Toyosawa, S., Yuki, M., Kishino, M., Ogawa, Y., Ueda, T., Murakami, S., ... \& Tomita, Y. (2007). Ossifying fibroma vs fibrous dysplasia of the jaw: molecular and immunological characterization. Modern Pathology,20(3), 389396.

16. Weinstein, L. S. (2006). Gs $\alpha$ Mutations in Fibrous Dysplasia and McCune- Albright Syndrome. Journal of Bone and Mineral Research, 21(S2), P120-P124.

17. Ogunsalu, C. O., Lewis, A., \& Doonquah, L. (1998). Benign fibro-osseous lesions of the jaw bones in Jamaica: analysis of 32 cases and report of a case. West Indian med. j, 47(suppl. 2), 51.

18. McCarthy, E. F. (2013). Fibro-osseous lesions of the maxillofacial bones. Head and neck pathology, 7(1), 5-10.

19. Alsharif, M. J., Sun, Z. J., Chen, X. M., Wang, S. P., \& Zhao, Y. F. (2009). Benign fibro-osseous lesions of the jaws: a study of 127 Chinese patients and review of the literature. International Journal of Surgical Pathology, 17(2), 122-134.

20. Abdulai, A. E., Gyasi, R. K., \& Iddrissu, M. I. (2004). Benign fibro-osseous lesions of the facial skeleton: an analysis of 52 cases seen at the Korle $\mathrm{Bu}$ Teaching Hospital. Ghana medical journal, 38(3), 96-100.

21. Prabhu S, Sharanya S, Naik PM, Reddy A, Patil V, Pandey S, Mishra A, Rekha K. Fibro-osseous lesions of the oral and maxillo-facial region: Retrospective analysis for 20 years. Journal of oral and maxillofacial pathology: JOMFP. 2013 Jan;17(1):36.

22. Sule, A. A., Iyogun, C. A., \& Adeyemi, T. E. (2017). Pattern of fibro-osseous lesions of the jaws in Kano, Northern Nigeria. J Dent Oral Heal, 3, 74.

23. Vegas Bustamante, E., Gargallo Albiol, J., Berini Aytés, L., \& Gay Escoda, C. (2008). Benign fibroosseous lesions of the maxillas: analysis of 11 cases. Medicina Oral, Patología Oral y Cirugia Bucal, 2008, vol. 13, num. 10, p. 653-656.

24. Iyogun, C. A., Dirisu, N., Omitola, O. G., \& Sule, A. A. (2018). Pattern of fibro-osseous lesions of jaws in Port Harcourt in South-South Nigeria. Annals of Medical and Health Sciences Research, 8(3).

25. Alsufyani, N. A., \& Lam, E. W. (2011). Osseous (cemento-osseous) dysplasia of the jaws: clinical and radiographic analysis. $J$ Can Dent Assoc, 77(70b), 1-8. 